\title{
Poverty, Denialism, Stigma and Discrimination: Challenges to Alleviating HIV/AIDS in Post-Apartheid South Africa
}

Samantha Manley

\begin{abstract}
South Africa is experiencing an HIV/AIDS epidemic whose prevalence remains the highest globally (UNAIDS, 2014). With an estimated 5.7 million HIV-positive persons in South Africa, it is pertinent to develop and sustain a multi-sector strategy for combating the HIV/AIDS epidemic which acknowledges poverty, denialism, stigma, and discrimination as social drivers, acting as deterrents towards treatment and awareness campaigns. These societal drivers are compounded by structural drivers which perpetuate vulnerability to HIV/AIDS. Intersectional stigma and discrimination act as barriers to effective treatment and prevention combination strategies which seek to decrease prevalence, especially amongst the most at risk populations (MARPs): Black women and youth, the LGBTQ community, intravenous drug users, the prison population, orphans, and sex workers (UNAIDS, 2011a; UNAIDS, 2014). These drivers not only perpetuate myths and misconceptions, but directly impact behaviour and decision-making capabilities. Black women and youth in urban and rural areas in South Africa represent one of the MARPs whose prevalence continues to increase, while other vulnerable groups prevalence has decreased or remains stagnant (UNAIDS, 2014). It is imperative to utilize the theory of intersectionality to better comprehend the relationship between poverty, denialism, stigma, and discrimination and its impact on the HIV/AIDS epidemic in South Africa.
\end{abstract}

Keywords: Poverty; denial; stigma; discrimination; South Africa; HIV/AIDS 
Abbreviations \& Acronyms:

$\begin{array}{ll}\text { AIDS: } & \text { Acute Immune Deficiency Syndrome } \\ \text { ART: } & \text { Antiretroviral Therapy } \\ \text { ARV: } & \text { Antiretroviral Drugs } \\ \text { HAART: } & \text { Hyper Active Antiretroviral Therapy } \\ \text { HIV: } & \text { Human Immunodeficiency Virus } \\ \text { MARP: } & \text { Most at risk population(s) } \\ \text { MTCT: } & \text { Mother-to-child-transmission of HIV } \\ \text { MSM: } & \text { Men who have sex with men } \\ \text { NGO: } & \text { Non-Governmental Organization } \\ \text { NSP1: } & \text { South Africa's National Strategic Plan for HIV, STIs and TB 2007- 2011 } \\ \text { NSP2: } & \text { South Africa's National Strategic Plan for HIV, STIs and TB 2012-2016 } \\ \text { PLWHA: } & \text { People Living with HIV/AIDS } \\ \text { STIs: } & \text { Sexually Transmitted Infections } \\ \text { TAC: } & \text { Treatment Action Campaign } \\ \text { THO: } & \text { Traditional Healers Organization } \\ \text { TRIPS: } & \text { Trade Related Aspects of Intellectual Property Rights } \\ \text { UNAIDS: } & \text { The Joint United Nations Programme on HIV/AIDS } \\ \text { WHO: } & \text { World Health Organization } \\ \text { LGBTQ: } & \text { Lesbian, Gay, Bisexual, Transgender and Queer }\end{array}$


The HIV/AIDS epidemic in South Africa has been exacerbated by an epidemic of poverty, denialist projections, stigmatizing behaviour, and discriminatory patterns. As a developing-industrialized nation, South Africa represents the highest Human Immunodeficiency Virus (HIV) and Acute Immune Deficiency Syndrome (AIDS) population in the world, with an estimated 5.7 million people infected (UNAIDS, 2012). South Africa accounts for $13 \%$ of the number of AIDS-related deaths globally (UNAIDS, 2014). Of these people, 3.2 million are women and 280,000 are children under the age of 14. Of South African adults aged 15 to 49, $17.8 \%$ are living with HIV, and there are almost 2 million South African children under the age of 17 who have been made orphans as a result of HIV/AIDS (UNAIDS, 2011b). The proportions of people who still do not have access to treatment are 58\% in South Africa (UNAIDS, 2014). Women, youth, and children are among the most vulnerable groups in the population and arguably are the most infected and affected groups in the country (NSP, 2012). Adolescent girls and young women account for one in four new HIV infections in sub-Saharan Africa and are the only most at risk population with an increasing prevalence rate (UNAIDS, 2014).

According to the International AIDS Society, HIV/AIDS is a social disease, requiring an analysis of both biomedical factors and societal/environmental factors. These societal drivers -social and cultural norms, beliefs, and values -- help express how HIV can acts in the capacity as the sum of multiple singular epidemics driven by factors such as denialism, stigma, and discrimination. The role of poverty, denialism, stigma, and discrimination in South Africa, which help comprise the complexity of the HIV/AIDS epidemic in the country, has become a major hindrance to South Africa's ability to adequately treat persons living with HIV/AIDS (PLWHA). The HIV/AIDS epidemic has been experiencing cycles of growth due to the fault lines in South African society, the inequity and inequalities experienced by many of the Black majority, the 
gender dynamics, and the widening divisions that continue to persist in the post-apartheid period (Pillat et al., 2013). South Africa's experience of ill health and inequality has become exacerbated by the high price of patented medicines, contributing to denialist accusations about pharmaceutical conglomerates seeking profit over health (Pillay et al., 2013). According to Mark Heywood (2010), “inequality affects health and ill-health creates new inequality.” The perpetuation of global ill-health inequalities participates in the continued spread of HIV/AIDS among many vulnerable groups in South Africa which do not adhere to a heteronormative bias: Black women and youth, the LGBTQ community, women who have sex with women (WSW), men who have sex with men (MSM), orphans, sex workers, intravenous drug users, and people in the prison system. For the purposes of this paper, Black women and youth residing in urban and rural areas will be analyzed as requiring more directive provenance campaigns within South Africa.

There is a strong relationship between poverty, inequality, and the spread of HIV which must be examined in coordination with the spread of denialism, stigma, and discrimination in South Africa in order to address gaps in treatment and prevention combination campaigns (Poku \& Whiteside, 2004). Denialism, stigma, and discrimination continue to act as deterrents towards the effectiveness of combination treatment and prevention campaigns. They not only perpetuate myths, misconceptions, and distrust, but directly impact behaviour and decision-making capabilities. This paper identifies poverty, denialism, stigma, and discrimination as part of the social and structural drivers which continue to affect South Africa's ability to engage in a unified response to the HIV/AIDS crisis. The key implications of the relationship between endemic poverty, AIDS denialism, and public health practices will be examined in coordination with intersectional stigma and discriminatory patterns to illustrate how these drivers act in the 
capacity of enablers of the epidemic. Utilizing a theoretical approach that is grounded in intersectionality will help to better articulate how stigma and discrimination in particular influence access to HIV services without building upon heteronormative assumptions (Logie, 2012). Race, gender, and class divisions will be examined to provide a more comprehensive understanding of barriers to treatment and prevention efforts. In order to illustrate the gaps in treatment and prevention, it is important to engage in discussions revolving around medical pluralism which includes traditional and Western forms of medicine. According to Barnett and Whiteside (2006) "treatment is not the starting point of the problem; it is the end-state." Developing appropriate awareness and preventative campaigns, in addition to treatment is of essential importance when attempting to combat the complex effects and affects associated with the virus.

\section{An Endemic of Poverty and Denial}

The HIV/AIDS pandemic in South Africa is representative of a multiplicity of epidemics which has imprinted itself on the existing structures and practices in the country (Poku \& Whiteside, 2004). It has helped to reveal the frailties and divisions in South African society, while illustrating patterns of inequality and social marginality. The high concentration of HIV among many Black South Africans in both rural and urban areas reflects patterns of vulnerability and inequality that are exacerbated by extreme poverty (Poku \& Whiteside, 2004). AIDS does not affect all in equal measure; it feeds off and aggravates existing inequalities (Fourie \& Meyer, 2010). Poverty is in many ways a major point of departure when discussing how the HIV epidemic is operating in South Africa. The cycle of povertyputs those poverty stricken groups not only at a higher risk of contracting HIV but also at a high risk of spreading the disease. If you live in poverty, you most likely have limited-to-no access to employment and are malnourished, 
hindering your ability to afford the medication to treat HIV (if you can access it) and have adequate nutritional levels to ensure that the medication will work (Poku \& Whiteside, 2004). The legacy of apartheid means that poverty and its connection to HIV/AIDS is a racialized and politicized issue (Fourie \& Meyer, 2010). As part of South Africa's policy of 'separate development,' the Black population was politically and materially marginalized (Fourie \& Meyer, 2010). Black South Africans received limited access to health services and educational opportunities as well as being confined to projects/areas, which helped encourage the unchecked spread of HIV (Fourie \& Meyer, 2010). Poverty has had a major impact on awareness campaign efforts in particular. With high rates of illiteracy, especially in English, these campaigns remained detached from some of the MARPs up until recently (Fourie \& Meyer, 2010). Those who are considered the MARPs found themselves in the position of the victim and vector of the HIV epidemic, through misinformation, minimal access to health services and poverty stricken conditions (Fourie \& Meyer, 2010).

There is a causal link between the absorption of denialist information, a country which suffers from an epidemic of poverty amongst many of the MARPs, and the spread of HIV because it provides a deterrence away from seeking treatment and deters preventative information from being absorbed and ultimately practiced by those who are effected and affected by the epidemic (Poku \& Whiteside, 2004). Denialism can be understood as actively propagating myths, misconceptions, and misinformation which seek to distort and or refute a particular reality (Kalichman, 2009). In the case of HIV/AIDS, there are numerous 'realities' that denialist or dissidents seek to negate: HIV does not cause AIDS, the governments are being controlled by conspiring forces, and that Highly Active Anti-retroviral Therapy (HAART) or ARV's are "toxic poison" (Kalichman, 2009, p.13). At the core of the denialist argument is its mistrust of Western 
forms of science and medicine and its attachment to conspiracy theories, which imply irrationality and implausibility, yet they remain logically possible and thus cannot be outright rejected (Nattrass, 2012). According to Nattrass (2012), AIDS conspiracy theories in particular can accompany denialist assertions that HIV does not cause AIDS and that HIV is harmless and ARVs actually cause AIDS. Although many of these theories have been scientifically disproven, they remain highly influential within South Africa and across the globe (Nattrass, 2012). "Denialism is to denial what activism is to action" (Kalichman, 2009, p.13). Denialists do not just spread (conspiracy) information; they actively campaign in order to persuade people to identify with their 'cause' (Kalichman, 2009; Nattrass, 2012). South Africa became vulnerable to denialist information most notably through the former president of South Africa Thabo Mbeki's active propagation of dissident information and its implementation into national policy (Kalichman, 2009).

There are many dissident scientists and members of academic and political communities that still support denialist claims about HIV/AIDS. In South Africa, there are three figures in particular who are responsible for the spread of dissident information; former President Thabo Mbeki, former Minister of Health, Manto Tshabalala-Msimang and Dr. Matthias Rath of the Dr. Rath Foundation (Nattrass, 2012). Closely following the coordination set forth by these personnel helps to explain how denialism became supported, not just through national policy, but through deliberate action. Thabo Mbeki's career came as a result of his electoral victory in the second national election held in the newly democratic country in 1999 (Van Dyk, 2012). His era is described as the darkest days in response to the HIV/AIDS epidemic in South Africa (Van Dyk, 2012). This era came to be characterized by a president who was influenced by dissident views and, in so doing, externalized such beliefs that HIV and AIDS were not linked and that 
HIV did not cause AIDS (Nattrass, 2012). In July of 2000, Mbeki first publically questioned the causal link between HIV and AIDS (Myburgh, 2007). When addressing the 13th International AIDS conference in Durban, South Africa, he stated that the "immune collapse among Black Africans could not be blamed on a single virus" (Myburgh, 2007). In an interview with Time Magazine, in September of that same year, Mbeki stated that, "the notion that immune deficiency (AIDS) is only acquired from a single virus (HIV) cannot be sustained" (Myburgh, 2007). What resulted from this statement and many that came after it was the perpetuation of the ill-treatment of PLWHA by not providing ARVs in the public health sector and instead promoting false information to the population, thereby disrupting global treatment and prevention campaigns and strategies (Geffen, 2010).

Mbeki's involvement in denialist discussions is deeply problematic for two reasons. Firstly, it injected new energy and respectability into a position that held no scientific credibility. Secondly, it undermined treatment and prevention campaigns involving the use of ARVs in the country (Nattrass, 2007, p.34). Mbeki's Minister of Health, Manto Tshabalala-Msimang relentlessly refused to support the distribution of ARVs in the public sector, especially for pregnant women (Geffen, 2010). The Treatment Action Campaign (TAC) successfully lobbied the government to provide Neviraphine (NVP) to HIV-positive pregnant women to reduce mother-to-child-transmission (MTCT) (Geffen, 2010). By the time of the court ruling, in favour of TAC in 2003, the prevalence rate of pregnant women in South Africa had already risen by $24.5 \%$ (Geffen, 2010). The increase of MTCT to newborns was due to the lack of available treatment and information in the public health sector, which was in a large part due to the denialist stance of the Mbeki government (Nattrass 2007; Van Dyk 2012). Constitutional Court Judge Edwin Cameron claims that it was the 'dead hand of denialism' that has accounted for 
government inaction (Nattrass, 2007, p.80), but it is arguably civil society and activism that has prompted the government to take action.

Dr. Rath, a known dissident, claims that ARVs are poisonous and the promotion of them has to do with supporting Western pharmaceutical companies, whereas he argues that vitamin conjunctions like beetroot, olive oil, lemon, and garlic, are the "cure for AIDS" (Low, 2010). This treatment is claimed to be a form of traditional medicine; however, Dr. Rath's methods are considered "quackery," because he claims that his treatment, VitaCell, is a "cure" for AIDS (Nattrass, 2007). Traditional healers do not claim to be able to "cure" their patients, but do claim to be able to treat symptoms of their condition (Nattrass, 2007; Wreford 2008). They do not always outright dismiss biomedical interventions/treatments as "toxic" and a ploy for profit by Western pharmaceutical companies as dissidents like Dr. Rath claim (Nattrass, 2007; Wreford, 2008). Dr. Rath was supported by the former Health Minister Manto Tshabalala-Msimang, thus putting him in a position that allowed him to prescribe such remedies, which inevitably resulted in many deaths from those who did not obtain ARVs or who gave them up and switched to the vitamin remedy (Cullinan \& Thom, 2009, p.126).

The Rath Foundation claims that AIDS can be "reversed by micronutrients alone" (Nattrass, 2007, p.148). TAC was responsible for lobbying the government to sanction Dr. Rath who conducted illegal trials in Gugulethu/Nyanga and Khayelitsha, townships in the Western Cape Province and tied him to the deaths of two people in the process of selling and distributing unlicensed substances and making false statements about the effectiveness of his product called VitaCell on HIV-positive persons (Cullinan \& Thom, 2009, p.128). Though the court hearings were to commence, Dr. Rath left the country in 2005, never to return to face the courts, though his publications and viewpoints continue to be distributed in the Traditional Healing 
Organization (THO) and across the country, which helps clarify the impact of denialism and its longevity across time and space (Cullinan \& Thom, 2009, p.128).

The relationship between Western medicinal practices and that of traditional healers in the context of the South African HIV/AIDS epidemic is important to examine in order to clarify the particulars of AIDS denialism longevity. There is a political normalization of the ART program which has taken hold in a structural form, but lingering myths, stigma, and a history of denialism and distrust of Western pharmaceuticals should be understood as a hindrance to the newly renewed AIDS agenda and policies which seek to normalize ART across the country (Gray et al., 2013). Despite the numerous triumphs the healthcare system has made in postapartheid South Africa, the country is still falling short in many regards, especially with its comprehensive understanding of how to manage and encourage the use of both Western medicinal practice and that of traditional African healers (Gray et al., 2013).

Traditional healing is representative of indigenous knowledge which uses herbal and spiritual methods/medicines as treatment (Wreford, 2008). The "choice" between traditional medicine and that of Western biomedical treatment is one which many South Africans face daily. Though the government has been successful in integrating the importance of traditional healing practices into policy, there is still limited engagement between the two and the likelihood of the MARPs having access to biomedical treatment is still quite limited given the number of available physicians and the level of awareness and comfortably experienced by many of the MARPs (Wreford, 2008). In South Africa, the traditional medicine sector is worth about R3billion (US\$280 million) a year and serves approximately 27 million people across the country (Cullinan \& Thom, 147, 2009). In South Africa there are an estimated 200,000 traditional healers while there is an average of only 25,000 medical practitioners thus making traditional medicine 
more accessible in a physical capacity (Malefetsane, 2012). Many traditional healers distinguish between diseases which western medicine or medical practitioners (doctors) can heal and treat and those which require traditional methods of healing which take on a medicinal, traditional, and spiritual form (Ashforth, 2002). Although terms like "traditional healing" can act as a catchall term, simplifying all traditional healing as homogeneous, it is still an important term to use to help clarify that there are other forms of healing and treatment that operate within South Africa that do not abide by biomedical standards. The World Health Organisation (WHO) has accepted that up to 80 per cent of the sub-Saharan population draws on the traditional healthcare sector for its primary healthcare needs (Ashforth, 2005). Although the WHO statistic is contested (as are most statistics relating to HIV in South Africa), there is evidence that many in subSaharan Africa are already engaging in "medical pluralism," drawing on both the biomedical and traditional healthcare sectors (Malefetsane, 2012). Traditional healers are integral to combination treatment and prevention campaigns given that they act as advisors, counsellors, and detectives within the community and, importantly, as conduits between community members and the ancestral realm (Wreford 2008). They have developed a relationship with their community in the absence of biomedical treatment (Wreford, 2008). Wreford (2008), a practicing sangoma (traditional healer) argues that collaboration between traditional healers and conventional health practitioners is both possible and desirable.

Effects of the agreement on Trade Related Aspects of Intellectual Property Rights (TRIPS), an international agreement administered by the World Trade Organization (WTO) (Heywood, 2002), have limited the access MARPs have to biomedical treatment in South Africa. TRIPS have had a profound impact on the production and distribution of HIV-related drugs. This WTO agreement undermines developing countries' abilities to produce more affordable generic 
versions of medicines, like ARVs, which are a necessary treatment for HIV-positive patients (Heywood, 2002). Procedures for parallel importation and compulsory licensing of HIV/AIDS drugs have been put into place, which have increased the access and mobility of HIV/AIDSrelated medicine, but the role played by pharmaceutical conglomerates like Pfizer have put South Africa in a compromising position (Heywood, 2002). The rollout of the South African government's treatment and testing campaign in 2010 marked a decisive shift in governmental response to the HIV/AIDS epidemic (Pillay et al., 2013). Not only did the South African Health Minister Dr. Aaron Motsoaledi negotiate a range of price reductions for antiretroviral treatment in a bid to increase access to treatment for PLWHA, but in so doing, contributed to the viability of South Africa's National Strategic Plan for HIV, sexually transmitted infections (STIs) and TB 2007-2011 and the most recent National Strategic Plan for HIV, STIs and TB 2012-2016, initiated by the current President of the African National Congress (ANC), Jacob Zuma. Though this marks a step in the right direction, more must be done. Though the pharmaceutical companies have had to lower prices over the last decade, barriers to treatment still persist with many of the fault lines still resting upon the price of brand named patented HIV-related drugs (Heywood, 2002; Pillay et al., 2013).

Since the launch of the government's treatment and testing campaign in 2010, ARVs as well as HIV testing are now offered to the public free of charge(Department of Health, 2013). This shift has provided South Africa with the opportunity to demonstrate its capacity to provide treatment and testing in spite of TRIPS barriers. The government is incurring the cost of the ARVs in order to take steps forward in providing treatment and access to testing that previously did not exist in the public sector (Gray et al., 2013). The efforts of civil society groups like the Treatment Action Campaign (TAC) and Médecins Sans Frontières (MSF), and the preceding 
government have contributed to 2 million people accessing ART/HAART as of December 2012 (Gray et al., 2013). As of April 2013, the South Africa government has begun distributing a fixed-dose combination (FDC) antiretroviral drug (Department of Health, 2013). The patients on the triple-therapy regimen will now be able to take just one pill daily to control the virus. This has the advantages of improving adherence and simplifying regimens so that prescribing errors are reduced, making it easier for patients to schedule appointments, while having the same effect as the previous multi ARV regimens (Department of Health, 2013).

\section{Conceptualizing Stigmatization \& Discrimination}

Stigma, stigmatization, and discrimination are intimately linked to the reproduction of social differences and as such cannot be understood in monodimensional terms (Parker \& Aggleton, 2003). The theory of intersectional stigma asserts that (multiple) stigmas interact with each other (Liampttong, 2013). The intersectionality of stigma and discrimination must be appropriated to the HIV/AIDS epidemic in order to grasp the complexities involved in administering combination treatment and prevention strategies in South Africa. Intersectionality highlights the interdependent and mutually constitutive relationships between social identities and social inequities, particularly relevant in the context of HIV-related stigma that exacerbates social and structural inequities based on race, class, gender, and sexual orientation (Logie, 2012). Intersectional approaches contend that no social group is homogenous (Simein, 2007). Such diverse life experiences ado not lend themselves to simple, categorical analysis based solely upon a single variant like gender (Simein, 2007). It is very important to acknowledge that heteronormative assumptions act as barriers to accessing HIV care and support and hinder adherence towards combination treatment and prevention campaigns (Logie, 2012). 
It is well documented that PLWHA experience stigma and discrimination on an ongoing basis, which is reproduced and strengthened by pre-existing inequalities such as race, class, gender, and sexuality (Skinner \& Mfecane, 2004; Parker \& Aggleton, 2003). Race and gender cannot be reduced to individual attributes to be measured and assessed for their separate contributions to the way in which the HIV epidemic is managed (Simein, 2007). That is to say, race, gender, and sexuality cannot be defined in terms of strict dichotomies (Simein, 2007). Class and socioeconomic status also play an important role in determining who becomes the MARPs within a country and contribute to the argument that linkages persist between poverty, conspiracy, denialism, stigma, discrimination, and the HIV/AIDS epidemic. In the case of South Africa, many Black women and youth in urban and rural townships are representative of the MARPs to the HIV/AIDS epidemic and require an analysis which does not adhere to heteronormative assumptions.

Deacon (2006) defines stigma as a socially constructed process operating at the individual, communal and national levels in which illness is constructed as preventable or controllable and 'immoral' behaviours causing the illness are identified and are associated with the social constructions of the 'other.' Certain people are thus blamed for their own infection and come to experience intersectional stigma (Deacon, 2006). Erving Goffman (1963) defines stigma as "an attribute that is significantly discrediting" and which serves to reduce the person who possesses it in the eyes of society. Relating the concept to a person with "an undesirable difference" (Goffman, 1963). In other words, he maintained that stigma is constructed by society on the basis of perceived 'difference' and is applied through the social. The result is a kind of 'spoiled identity' for the person concerned (Goffman, 1963). When race, class, sexuality, and gender identity combine with a health condition such as, HIV/AIDS, it contributes 
to the experience of intersectional stigmas, which in turn hinders awareness and treatment and prevention combinations campaigns' effectiveness.

There are many forms of stigma that HIV-infected and affected persons are experiencing in post-apartheid South Africa. Enacted stigma refers to the experience of discrimination, which constitutes acts in which the content of the stigma is applied to individuals and/or communities (Skinner \& Mfecane, 2004). Stigma consists of the labeling difference, associating human difference with negative attributes, the separation of those who are different from those who are 'normalized' and lastly status and position loss (Skinner \& Mfecane, 2004; Deacon, 2006). Stigma and the act of stigmatization performed by individuals, communities, and governments consciously or unconsciously, are dependent on social, economic, political, cultural, and religious forces that hold a degree of power and influence within a given society (Skinner \& Mfecane, 2004). This power and influence, once enacted, is sustained through the enforcement of the components of stigma demonstrated above. Stigma can be enacted, internalized, and perceived by individuals, communities and nations (Sinner \& Mfecane, 2004). The nature of stigma and discrimination both separately and together is complex, varying across time, person and context, making analysis and intervention very difficult. In South Africa, HIV-related stigma continues to persist and becomes heightened as it becomes compounded by other stigmas through the intersectionality associated with race, gender, sexuality and class (Simein, 2007). HIV-related stigma does not only affect those who have an association with the virus, but it perpetuates the exclusion of many Black South Africans who have already been stigmatized throughout history. The visibility of stigma plays an important role in that it has the ability to hinder prevention efforts and reduce the impact factor of treatment and prevention combination campaigns initiated and supported by the government, non-governmental organizations (NGOs), 
as well as community members. The use of condoms for example, is a barrier method, which has become tainted by stigma and as a result, has influenced behaviours of youth in particular to reject the use of condoms (Abdool Karim \& Abdool Karim, 2006). Low rates of condom use signify the extent to which HIV-related stigma has hindered responses to alleviate HIV/AIDS in the country (Abdool Karim \& Abdool Karim, 2006). Some of the perceptions about condom use that act as barriers to frequent or even rare condom use include the perception that condoms are used in high-risk sexual relationships, their association with infidelity, lack of trust between partners, the person requesting must be infected or believe their partner to be infected with a STI, and lastly the issue of condoms decreasing pleasure (Abdool Karim \& Abdool Karim, 2006). The latter points are more relevant to our discussion.

Used correctly, condoms are highly effective in preventing the transmission of HIV through sexual activity (Abdool Karim \& Abdool Karim, 2006). Male condoms with the brand name "Choice" have been made freely available to the public by the Department of Health in coordination with AIDS Help Line (Department of Health, 2013). These male condoms can be found in most public arenas and restrooms in city centres. By branding the condoms in this way, the government is presuming and sending a message to the public that men have the choice to engage in safe sexual behaviour, whereas women must be inclined to follow the "choice" of their male counterparts, regardless of their sexual orientation or willingness to participate. This campaign of male choice and female submission therefore increases the stigma and myth of women being HIV- positive for engaging in high-risk or unsafe sexual behaviour (Van Dyk, 2012). In South Africa, female condoms are expensive and have not been made widely available and can only be accessed through family planning centres (Van Dyk, 2012). While research has found that the overwhelming majority of South Africans believe that condoms are easily 
accessible, this is not the case among the MARPs and especially for those who do not have access to mobile and formal clinics, which is unnervingly common.

Gender hierarchy is a fundamental factor in the epidemic, which has led to expectations of female obedience and male dominance and sexual entitlement through a culturally divulged and socially perpetrated patriarchal attitude (Pillay et al., 2013). Gender-related stigma within the confines of the epidemic helps contribute to disturbing myths about HIV transmission and means of "curing" HIV. By this I mean the perpetuation of myths that include curing or not contracting HIV/AIDS by having sexual relations with a virgin and/or a baby/child (Van Dyk, 2012). These myths are detrimental to the safety and well-being of women and youth throughout the country. Such myths have helped to increase the rate of rape experienced by women for a country that is not in conflict (Engel, 2006). In South Africa, women are said to be victims of rape every 26 seconds (Engel, 2006 p.230). Gender-related stigma in the context of the HIV/AIDS epidemic reinforces pre-existing economic, educational, cultural, and social disadvantages and unequal access to information and services that women have been experiencing in South Africa before the epidemic (Van Dyk, 2012). Overall, race, class, sexuality, and gender-related stigma in the context of HIV remain impediments to combination treatment and prevention campaigns. According to UN Secretary General Ban Ki Moon, "stigma remains the single most important barrier to public action," and "stigma is a chief reason why the AIDS epidemic continues to devastate societies around the world" (UNAIDS, 2010) and South Africa is no exception. Although stigma is considered a major barrier to effective responses to the HIV/AIDS epidemic, stigma reduction efforts are demoted to the bottom of AIDS program priorities (Mahajan et al., 2008). The complexity of HIV/AIDS related stigma is often cited as a primary reason for the 
limited response to this pervasive phenomenon, yet it is followed up with a limited response (Mahajan et al., 2008).

Discrimination is a variable that is enacted in coordination with stigma to produce a separation between 'us' and 'them' (Mahajan et al., 2008). In the context of the HIV/AIDS epidemic, discrimination impacts not just people's ability to disclose their status to their partners and or community members, but it also encourages people to disassociate themselves with the HIV virus even if they have been infected (Liamputtong, 2013). The acknowledgment of being HIV-positive and all that comes with the diagnosis becomes clouded by perceptions of discrimination and discriminatory measures which may be enacted, which eventually become lived realities when the HIV-positive person either experiences, witness or contributes to discrimination (Skinner \& Mfecane, 2004). HIV/AIDS-related discrimination take different forms and is manifested at different levels including the societal, communal and individual (Liamputtong, 2013). From a societal perspective, HIV/AIDS is associated with marginalized behaviours and groups (Liamputtong, 2013). At the societal level, AIDS-related discrimination is manifested through denied opportunities such as travel, use of healthcare facilities, employment and education (Liamputtong, 2013). South Africa has worked to amend such discriminatory actions, and has been particularly successful in its efforts to ensure access to these services and opportunities for PLWHA, but it has done so by endorsing non-disclosure and in so doing, endorsing a silencing of HIV/AIDS (Van Dyk, 2012).

The silencing of the epidemic is contributing to enhanced stigma and discriminatory behaviour. Although there are peer-support groups within these facilities, the non-disclosure aspect is hindering the country's ability to heal and move forward while alleviating the variables which contribute to the strength and persistence of the epidemic (Van Dyk, 2012). Examples of 
such discriminatory practices which have been amended include pre-employment screening, denial of employment to individuals who test positive, and termination of employment (Liamputtong, 2013). At the communal level, discrimination comes from the family and the church and instills fear in individuals that they will be shunned from their communities, leading once more to the non-disclosure of HIV status, which could result in more high-risk activities (Liamputtong, 2013). This fear is then placed on testing and treatment. For the some individuals, delaying diagnosis sets aside the fear that is associated with HIV/AIDS and places it instead on stigma and discrimination (Van Dyk, 2012). The problem with the delay in testing and treatment is the potential spread of HIV unto others. The benefit of getting tested and receiving treatment is arguably outweighed by the discrimination they are fearful of and the stigmatization they have or will come to experience following the results (Van Dyk, 2012). In many respects, there is more fear associated with stigma and discrimination than with HIV.

In South Africa, the family is the main source of care and support for PLWHA and the discriminatory actions and behaviours that are enacted by family members and friends can counteract any sort of trust the HIV-positive person may have felt, therefore acting as a barrier to the safety of the PLWHA and those without (Van Dyk, 2012). However, not all family members have negative reactions to disclosure, which include blame, rejection, and loss of children and home, and, more often than not, women and young girls experience a higher frequency of negative responses (Van Dyk, 2012). Negative reactions come as a result of pre-existing stigma, which suggests that HIV/AIDS is associated with high-risk sexual behaviour and promiscuity, though this presumes that women and young girls willfully engaged in acts of this nature (Van Dyk, 2012). At the individual level, discrimination undermines a person's identity and ability to disclose status and in turn limits an individual's capacity to seek treatment or engage in risk- 
averse activities (Liamputtong, 2013). But individual behaviour is highly influenced by societal norms and social and cultural constructions (Van Dyk, 2012). It is therefore imperative to address how gender norms and heteronormativity perpetuate discrimination and stigma, especially towards women.

In South Africa, heteronormative bias and cultural perceptions of masculinity and femininity influence combination treatment and prevention HIV/AIDS campaigns, while also perpetuating stigmatization and discriminatory behaviour. Major obstacles in implementing such programs is the gender imbalance in knowledge production, including the role of patriarchy and how this operates within sexual relationships (Van Dyk, 2012). The fear of violence and financial dependence is another variable which places marginalized women in more vulnerable positions to the HIV epidemic (Van Dyk, 2012). Intergenerational relations and age of sexual debut are two emerging variables that are impacting prevention efforts. According to UNAIDS statistics, in 2007, persons aged 15-24 accounted for an estimated 45\% of new HIV infections worldwide (Shisana et al., 2009). In the South African context, HIV/AIDS prevalence among young females in this age group is three to four times more likely than their male counterparts (Shisana et al., 2009). Unequal power dynamics which become reproduced with HIV-related stigma, through a gendered and age-based lens increase the vulnerability of girls and those who engage in relationships with "sugar daddies" or older gentlemen to exacerbate their risk of contracting HIV/AIDS, given that the ability to negotiate safe sexual practices (such as condom use, monogamous relations, HIV/AIDS and STI testing) remains limited or nonexistent (Shisana et al., 2009). It has been found that earlier sexual debut increase a person's chances of contracting HIV/AIDS; however, the 'choice' about when to debut oneself sexually does not always rest in the hands of the female, leaving them vulnerable not just to unwanted sexual 
encounters, but to the stigma and discrimination that becomes layered in the context of HIV/AIDS transmission (Shisana et al., 2009).

\section{Concluding Remarks}

The 5.7 million people who are HIV-positive in South Africa represents one sixth of the epidemic globally (UNAIDS, 2010). In order for treatment and prevention to become more accessible, the relationship between poverty, denialism, stigmatization, and discrimination need to become a heightened priority on the AIDS agenda. HIV- related stigma and discrimination are complex social processes. They are neither unique nor randomly patterned (Skinner \& Mfecane, 2004). They usually build upon and reinforce pre-existing fears, prejudices and social inequalities pertaining to poverty, gender, race, sex, and sexuality, and therefore it seems viable to suggest that until denialism, stigma and discrimination are prioritized as significant factors, these variables will remain hindrances to the successful roll-out and accessibility of combination treatment and prevention campaigns in South Africa.

Although South Africa has a progressive constitution and legal framework regarding the rights of marginalized groups, this has not translated into policy and programming when combined with the HIV/AIDS epidemic (UNAIDS, 2011a): "Inequality in post-apartheid South Africa has, in many instances, retained its apartheid face" (Pillay et al., 2013, p.20). It is an increasingly acknowledged reality today that throughout the world those most deeply affected by the HIV/AIDS epidemic are also the most severely disadvantaged, whether on grounds of race, economic status, age, sexual orientation, or gender (Skinner \& Mfecane, 2004). Health epidemics like HIV/AIDS, follow a "social gradient: the lower the socioeconomic position, the worse the health" (Pillay et al., 2013, p.472). Though the visibility of HIV has increased substantially over the last decade, the process of de-stigmatization surrounding HIV has not 
followed suit. The government in coordination with other actors has launched its third phase of the NSP2, which seeks, in coordination with UNAIDS Getting to Zero campaign, to combat stigma and discrimination, yet the perception that denialism ended with the Mbeki era is a hindrance to the goals set out by these campaigns (NSP2, 2012). In order for a sustainable combination campaign to reverse the damage caused by the epidemic and move towards a sustainable, healthier future, poverty, denialism, stigma, and discrimination need to be addressed in tandem as social drivers by political and social forces alike. 


\section{References}

Ashforth, A (2002). An Epidemic of Witchcraft? The Implications of AIDS for the PostApartheid State. Social Dynamics: A Journal of African Studies, 61(1), 121-143.

Asforth, A. (2005). Muthi, Medicine and Witchcraft: Regulating 'African Science' in PostApartheid South Africa? Social Dynamics: A Journal of African Studies, 31(2), 211-242.

Abdool Karim S. S., and Abdool Karim Q. (2006). HIV/AIDS in South Africa. Cape Town: Cambridge University Press.

Barnett, Tony, and Alan Whiteside (2006). AIDS in the Twenty-first Century: Disease and Globalization. Basingstoke England: Palgrave Macmillan.

Cullinan, Kerry, and Anso Thom (2009). The Virus, Vitamins and Vegetables: The South African HIV/AIDS Mystery. Auckland Park, South Africa: Jacana.

Deacon, H. (2006). Towards a sustainable theory of health-related stigma: lessons from the HIV/AIDS literature. Journal of community \& applied social psychology, 16(6), 418-425.

Department of Health: Fixed Dose Combination (FDC) Antiretrovirals (2013). South African Government: Health.

Fourie, Pieter, and Melissa Meyer.(2010) The Politics of AIDS Denialism: South Africa's Failure to Respond. Farnham, Surrey, England: Ashgate Pub.

Geffen, Nathan (2010). Debunking Delusions: The inside Story of the Treatment Action Campaign. Auckland Park, South Africa: Jacana Media.

Goffman, E. (1963). Stigma: Notes on the Management of a Spoiled Identity. New York: 
Simon and Schuster.

Gray A, Vawda Y, Jack C (2013). South African Health Review 2012/13. Health Policy and Legislation. Durban: Health Systems Trust. Pp. 1-34.

Heywood, Mark. (2010). Drug access, patents and global health: 'Chaffed and waxed sufficient.' Third World Quarterly. 23:2 Pp.217-231.

International AIDS Society (IAS). Social and Political Research. International AIDS Society. http://www.iasociety.org/Default.aspx?PageId=572

Kalichman, Seth C (2009). Denying AIDS: Conspiracy Theories, Pseudoscience, and Human Tragedy. New York: Copernicus.

Liamputtong, P. (2013). Stigma, discrimination and living with HIV/AIDS: a cross-cultural perspective. Springer.

Low, Marcus (2010). Fighting for Our Lives: The History of the Treatment Action Campaign 1998-2010. Cape Town: Treatment Action Campaign.

Mahajan AP, Sayles JN, Patel VA, et al (2008). Stigma in the HIV/AIDS epidemic: a review of the literature and recommendations for the way forward. AIDS. National Institute of Health. 22:S67-79.

Malefetsane, S. (2012). Medical practitioner versus traditional healers: Implications for HIV \& AIDS policy. Consultancy Africa Intelligence (CAI).

Myburgh, James (2007). Here is the evidence of Mbeki's denialism. Politics Web. http://www.politicsweb.co.za/politicsweb/view/politicsweb/en/page71619?oid=82478\&s $\mathrm{n}=$ Detail 
Nattrass, Nicoli (2007). Mortal Combat: AIDS Denialism and the Struggle for Antiretrovirals in South Africa. Scottsville, South Africa: University of KwaZulu-Natal.

Nattrass, Nicoli (2012). The AIDS Conspiracy: Science Fights Back. New York: Columbia University Press.

Parker, R., \& Aggleton, P. (2003). HIV and AIDS-related stigma and discrimination: a conceptual framework and implications for action. Social science \& medicine, 57(1), 13 24.

Pillay, Udesh, Gerard Hagg, Francis B. Nyamnjoh, and Jonathan D. Jansen (2013). State of the Nation: South Africa, 2012-2013. Cape Town: HSRC.

Poku, Nana, and Alan Whiteside (2004). The Political Economy of AIDS in Africa. Aldershot, Hants, England: Ashgate.

Shisana O, Rehle T, Simbayi LC, Zuma K, Jooste S, Pillay-van-Wyk V, Mbelle N, Van Zyl J, Parker W, Zungu NP, Pezi S \& the SABSSM III Implementation Team (2009). South African national HIV prevalence, incidence, behaviour and communication survey 2008: A turning tide among teenagers? Cape Town: HSRC Press

Skinner D. and Mfecane S. (2004). Stigma, discrimination and the implications for people living with HIV/AIDS in South Africa. Journal of Social Aspects of HIV/AIDS. Vol 1. No 3. Pp. $157-164$

The National Strategic Plan (NSP) on HIV, STIs \& TB 2007-2011 (2007). The South African National AIDS Council (SANAC). Pp. 1-35. 
The National Strategic Plan (NSP) on HIV, STIs \& TB 2012-2016 (2012). The South African National AIDS Council (SANAC). Pp. 1-82.

UNAIDS (2014). The Gap Report. Geneva, Switzerland: Joint United Nations Programme on HIV/AIDS

UNAIDS (2012). UNAIDS Report on the Global AIDS Epidemic 2012. Geneva, Switzerland: Joint United Nations Programme on HIV/AIDS.

UNAIDS (2011a). Community innovation: sexual and reproductive health and rights through the HIV response. Geneva, Switzerland: Joint United Nations Programme on HIV/AIDS.

UNAIDS (2011b). UNAIDS 2011-2015 Strategy: Getting to Zero. Geneva, Switzerland: Joint United Nations Programme on HIV/AIDS.

UNAIDS (2010). South Africa Expanding Access to ARV Therapy. Geneva, Switzerland: Joint United Nations Programme on HIV/AIDS.

Van Dyk, Alta (2012). HIV and AIDS Education, Care and Counselling: A Multidisciplinary Approach. Cape Town: Pearson Education. 